\title{
THE EVALUATION OF SINANODONTA WOODIANA APPLICATION FEASIBILITY AS A MICROCYSTIS-BLOOMING REMOVAL TOOL IN MICROCOSM EXPERIMENTS
}

\author{
Yuxian $\mathrm{LIU}^{1^{*}}$, Aimin $\mathrm{HAO}^{2}$, Yasushi ISERI ${ }^{3}$, Chunjie $\mathrm{LI}^{4}$, Zhenjia ZHANG ${ }^{4}$ and \\ Takahiro KUBA ${ }^{1}$ \\ ${ }^{1}$ Graduate School of Engineering., Kyushu University. \\ (744 Motooka, Nisi-ku, Fukuoka 819-0395, Japan) \\ ${ }^{2}$ Research Institute for East Asia Environments, Kyushu University. \\ (744 Motooka, Nisi-ku, Fukuoka 819-0395, Japan) \\ ${ }^{3}$ West Japan Engineering Consultants, Inc., Japan. \\ (1-1-1 Watanabe Road, Chuo-ku, Fukuoka 810-0004, Japan) \\ ${ }^{4}$ School of Environmental Science and Engineering., Shanghai Jiaotong University. \\ (800 Dongchuan Road, Shanghai 200240, China) \\ *E-mail: axian87@gmail.com
}

\begin{abstract}
Sinanodonta woodiana is widely distributed throughout Chinese freshwaters and is an important economic pearl mollusk. In order to evaluate the application feasibility of $S$. woodiana as a Microcystis-blooming removal tool, a series of microcosm experiments were performed. First, the 6-day feeding responses experiment was carried out with naturally blooming pond water and the bivalves in laboratory, which was lasted for 6 days. In this experiment, phytoplankton abundances and community structure were analyzed on 0-day and 6-day for both control and treatment microcosms; also, filtration rate, absorption efficiency, oxygen consumption rate and ammonia excretion rate of $S$. woodiana were measured on 0-day and 6-day and finally the scope for growth (SFG) value as a measure of metabolic energy balance for S. woodiana was calculated and compared. The results showed that Microcystis spp. of colony and unicell were reduced obviously on the 6-day; meanwhile, after six days' exposure to Microcystis-blooming pond water, the SFG value for $S$. woodiana increased. Furthermore, in the extended long-term grazing experiment, bivalves were fed with highly concentrated toxic Microcystis-blooming water and non-toxic Chlorella at the constant concentration $\left(\mathrm{Chl} . \mathrm{a}=424.5 \mathrm{mg} / \mathrm{m}^{3}\right)$ in two respective tanks for 12 days. No bivalve mortality was registered on both Chlorella group and blooming water group. In addition, SFGs were significantly higher for the blooming water group, compared with them for Chlorella group on 3-day, 6-day and 12-day. These results indicated that toxic Microcystis spp. in natural eutrophic water can be removed greatly by $S$. woodiana; moreover, the bivalves themselves have strong adaptation ability when they were exposed to toxic natural eutrophic water. Therefore, it can be inferred that there is high application feasibility of $S$. woodiana as a Microcystis-blooming controller in practice.
\end{abstract}

Key Words : Sinanodonta woodiana, Microcystis-blooming, SFG (scope for growth), microcystins (MCs), application feasibility

\section{INTRODUCTION}

The bivalve Sinanodonta (Anodonta) woodiana ${ }^{1)}$ is widely distributed throughout Chinese freshwaters and is an important economic pearl mollusk; as a benthic suspension filter feeder, it is also capable of filtering a variety of sestonic particles, including phytoplankton, detritus, small zooplankton and bacteria, as well as dissolved organic matter ${ }^{2}$. In Chinese Lake Taihu, where Microcystis blooms frequently especially in summer, abundant $S$. woodiana can be sampled in the lakes especially in 
the littoral zones.

Previous studies have generally focused on the effects of bivalves on water body. Intensive $S$. woodiana has been promoted as a biomanipulation tool of lakes in China and strong suppression of phytoplankton, apparent changes of phytoplankton community structure and the improvement of water transparency were observed ${ }^{3)}$. Yet relatively little is known about the grazing effect of $S$. woodiana on toxic cyanobacterial blooms and the effects of long-term exposure to natural eutrophic water on the growth and physiological energetics.

In our previous study, laboratory experiments were carried out to compare the mussel $A$. (S.) woodiana's acute physiological responses to variable microalgae diets, including toxic microcystin-producing cyanobacteria Microcystis aeruginosa NIES-90 and non-toxic green algae Scenedesmus obliquus, and it was found that $A$. (S.) woodiana's has a higher grazing ability on the toxic microcystin-producing cyanobacteria $M$. aeruginosa than that of non-toxic green algae S. obliquus ${ }^{4}$.

However, M. aeruginosa cultured in the laboratory was unicell and could not form colonial type as in natural blooms. Moreover, the effects of long-term immersion to natural eutrophic water with both colonial and unicellular Microcystis spp. on the growth and physiological energetics, which is an integration of several physiological processes, of bivalve mollusks have not been widely studied yet.

"Scope for growth" (SFG) measurement, which measures the energy available for growth, has been widely used in many ecotoxicological studies ${ }^{5)}$. This measurement of physiological energetics, normally in terms of SFG, can provide instantaneous assessment of the growth process of bivalves as affected by environmental stress and pollution. SFG is measured by integrating several physiological parameters, including filtration rate, absorption efficiency, respiration rate and ammonia excretion rate, all of which can directly affect the energy available for growth, maintenance and reproduction of bivalves. Many studies have indicated the advantages of assessing the physiological status of bivalves by measurement of SFG rather than individual physiological process ${ }^{6}$. Although this physiological biomarker has been widely applied in assessing the physiological condition of bivalves, there is no study that applied this biomarker to determine the effects of natural Microcystis-blooming water on freshwater bivalves. With a growing concern on the impact of eutrophic water, it is clear necessary to assess whether eutrophic water has a negative impact on the growth of shellfish in this region.

Therefore, the aim of this paper is to examine whether the most popular native mussel $S$. woodiana can exert grazing pressure on naturally blooming Microcystis spp. through evaluating the effect of $S$. woodiana's feeding behaviour on phytoplankton abundances and community structure and then assess whether eutrophic water has a negative impact on the growth of $S$. woodiana through introducing SFG related to energetic balance of $S$. woodiana.

Thus, in this study we performed a series of microcosm experiments with naturally Microcystisblooming water which contained large quantities of colonial Microcystis spp.. First, the 6-day feeding responses experiment was carried out with naturally blooming pond water and the bivalves in laboratory, which was lasted for 6 days. In this experiment, a comparative analysis of the algae presented in the control tank and treatment tanks on 0-day and 6-day was performed; in addition, the SFG values of bivalves on 0-day and 6-day were compared. Furthermore, the extended long-term grazing experiment was carried out. Bivalves were fed with two types of food: highly concentrated naturally blooming Oita water dominated by Microcystis spp., containing high concentrations $(25.50 \mu \mathrm{g} / \mathrm{L})$ of toxin, and non-toxin green algae Chlorella at the same Chlorophyll a concentration of $424.5 \mathrm{mg} / \mathrm{m}^{3}$ in two respective tanks for 12 days. On 0-day, 3-day, 6-day, and 12-day, the grazing rates and metabolic rates were measured and finally SFGs were calculated and compared.

These results obtained may lead to a comprehensive assessment of the application possibility of $S$. woodiana as a Microcystis-blooming removal tool in eutrophic shallow lakes.

\section{6-DAY FEEDING RESPONSES EXPERIMENT}

\section{(1) Materials}

$S$. woodiana was supplied by Gunma Prefecture in Japan. The bivalves were kept at $4{ }^{\circ} \mathrm{C}$ before transporting them to the laboratory. Immediately upon arrival, the bivalves were transferred to $35 \mathrm{~L}$ aquaria with $20 \mathrm{~L}$ aerated dechlorinated tap water at controlled temperature $25{ }^{\circ} \mathrm{C}$, under a light:dark regime of $12 \mathrm{~h}: 12 \mathrm{~h}$ for at least one week, before being used for experiments. The water was completely refreshed three times per week. Source water applied in our test was from a pond in the central part of Chikushino city, Fukuoka, Japan. In the pond, the cyanobacterial bloom was a growing problem due to increasing eutrophication resulting from agricultural pollution and domestic sewage.

The pond was characterized by summer cyanobacterial bloom (Microcystis spp.) from June to 
October. Besides Microcystis spp., some other species such as Nitzschia spp. and Chlorella sp. were also observed by microscopy in the pond water. The characteristics of raw water are listed in Table 1.

Table 1 Raw water quality of pond water.

\begin{tabular}{|lc|}
\hline Parameter & Value \\
\hline $\mathrm{pH}$ & 8.3 \\
Total nitrogen $(\mathrm{mg} / \mathrm{L})$ & 3.0 \\
Total phosphorous $(\mathrm{mg} / \mathrm{L})$ & 0.08 \\
Phytoplankton (cells $/ \mathrm{mL})$ & $5.8 \times 10^{5}$ \\
Chlorophyll a $\left(\mathrm{mg} / \mathrm{m}^{3}\right)$ & 120.0 \\
\hline
\end{tabular}

\section{(2) Methods}

The experiments were performed at controlled conditions $\left(25 \pm 1{ }^{\circ} \mathrm{C}, 12 \mathrm{~h}\right.$ light:dark cycle, 3400 lux $)$ in four tanks $(40 \mathrm{~cm} \times 25.2 \mathrm{~cm} \times 26.2 \mathrm{~cm})$. One tank was set as control filled with 20 L Microcystis-blooming pond water with a layer (10 $\mathrm{cm}$ ) of pond sediment (the same pond to resource water) without bivalves; the other three replicated tanks were set as treatment at the same condition with bivalves. The bivalves of similar size (shell length of $7.45 \pm 0.41 \mathrm{~cm}$ and fresh-weight of $42.15 \pm$ $7.69 \mathrm{~g}$ ) were chosen and kept in the three replicated treatment tanks ( $\mathrm{n}=3$ per tank). During the experiment, constant aeration was supplied. Sediments were supplied to simulate the natural condition and the bivalves' habitat. Before introduction to the tanks, bivalves were gently cleaned with a brush under running de-ionized water to remove phytoplankton adhered to the shell and not fed for 2 days in clean aerated dechlorinated tap water to clear the guts ${ }^{7}$.

Bivalves were fed with Microcystis-blooming pond water for 6 days. We quantified the SFG in bivalves on 0-day and 6-day for treatment microcosms.

\section{a) Phytoplankton abundances and community structure analysis and identification}

$15 \mathrm{~mL}$ water samples for phytoplankton community structure analysis were collected on 0-day and 6-day in the control and treatment microcosms. They were preserved with $5 \%$ formalin. After complete mixing, samples were counted directly through a $0.1 \mathrm{~mL}$ counting chamber using a microscope at 400 magnification. Specific identification of phytoplankton was made according to the Illustration of the Japanese Freshwater Algae ${ }^{8)}$.

\section{b) Filtration rate measurement}

The filtration rate $(\mathrm{FR}, \mathrm{mL} / \mathrm{g} \mathrm{FW} / \mathrm{h})$ of each individual bivalve, defined as the volume of water cleared per unit time was determined by the time course of the decrease of algal density due to bivalve filtration. The experiment began when the shell valve of the bivalve opened. Chl.a concentration in the pond water was measured every one hour, for a total of 4 hours on 0-day and 6-day.

The algae solution was stirring gently each time suspended food was sampled at certain intervals of time to keep food in suspension and homogeneous. The Chl.a concentration was measured by fluophotometer. The FR was determined by the following formula, which has been used in modified form by many other authors ${ }^{9}$ :

$$
F R=(V /[w t]) \operatorname{Ln}\left[C_{0} / C_{t}\right]
$$

In which $V$ is the volume of the food suspension (20 $\mathrm{L}), w$ is the fresh weight of the mussels in each vessel $(\mathrm{g}), t$ is the duration of the experiment (in hour), $C_{0}$ is the Chl.a concentration $(\mathrm{mg} / \mathrm{L})$ at 0 or one time step before $t$ and $C_{t}$ is the algae concentration at time $t$. In the vessels with mussels the algae concentration was corrected for changes observed in the control vessels.

The amount of ingested or consumed energy (C) was calculated for each individual by multiplying FR by the amount of particle organic material (POM) per liter in input water samples and assuming an energy content of algal material of $23 \mathrm{~J} / \mathrm{mg}^{10}$.

\section{c) Respiration rate measurement}

The respiration rate $\left(\mu \mathrm{g} \mathrm{O}_{2} / \mathrm{g} / \mathrm{h}\right)$ of bivalves was measured by respirometers in enclosed chambers $(1200 \mathrm{~mL})$ full of Microcystis-blooming water used in filtration rate measurement experiments on 0-day and 6-day. The bivalves were isolated from the treatment tanks after the filtration rate measurement and transferred into corresponding enclosed chambers. A chamber without a bivalve was used as a control. Pond water in the chamber was mixed by a magnetic stirrer placed on the bottom. The oxygen concentration in the pond water was detected by an oxygen electrode. Measurement of oxygen concentration commenced when the animals opened their shell valves and lasted for 2 hours in darkness. Oxygen concentration was plotted against time of measurement and respiration rate was calculated from the slope of the decrease of oxygen concentration over time during two hours. The amount of energy used in respiration (R) was calculated assuming an energy content of 0.456 $\mathrm{J} / \mu \mathrm{mol} \mathrm{O}{ }_{2}{ }^{11)}$.

\section{d) Absorption efficiency measurement}

The absorption efficiency of the organic matter by mussels was determined by the ratio method ${ }^{12)}$. This method assumed that the absorption of the inorganic component of food was insignificant during the digestive process. After the respiration rate 
measurement on 0-day and 6-day, the bivalves were placed into three vessels with $2 \mathrm{~L}$ aerated dechlorinated tap water. Any feces egested were collected after 12 hours. The feces were filtered onto a preweighted GFF. The filters were subsequently ashed in a muffle furnace at $450{ }^{\circ} \mathrm{C}$ for $1 \mathrm{~h}$, and the loss of organic matter was calculated. The absorption efficiency (AE) was calculated by comparing the ratio of organic and inorganic materials between the food and feces, by the following equation ${ }^{12)}$ :

$$
A E(\%)=(F-E) /[(1-E) \times F] \times 100
$$

Where $F$ is the ash-free dry weight:dry weight ratio (AFDW/DW) of the food and $E$ is the ash-free dry weight:dry weight ratio of feces.

\section{e) Excretion rate}

Another component of metabolic loss is presented by the products of excretion. The excretion rate (ER; $\mathrm{mg} \mathrm{NH}_{4}{ }^{+} \mathrm{N} / \mathrm{h}$ ) measurement was performed simultaneously with the filtration rate measurement. After the collection of Chl.a with GFC filter paper (Whatman), the filtered water samples were measured for ammonium ion concentration with Ion Chromatography ICS-2100_ICS-1100_AS.

Ammonium ion concentration was plotted against time of measurement and excretion rate was calculated from the slope of the decrease of ammonium ion concentration over time (ammonium ion concentration was measured every 30 minutes). The amount of energy used in excretion (U) was calculated for each individual by multiplying ER by assuming an energy content ammonium ion of 19.4 $\mathrm{J} / \mathrm{mg} \mathrm{NH}_{4}{ }^{+13)}$.

\section{f) $\mathrm{O} / \mathrm{N}$ ratio}

Another biomarker used to indicate the physiological state of the organism in this case exposed to Microcystis-blooming pond water is the quantification of oxygen-nitrogen atomic ratio $(\mathrm{O} / \mathrm{N})$. This biomarker is the result of the quantification division of oxygen uptake and the quantification of ammonia excretion in atomic equivalent. It was calculated to determine the proportion of protein relative to carbohydrate and lipid catabolized for energy metabolism ${ }^{14)}$.

g) Calculation of scope for growth (SFG)

The SFG, which defined the energy available for growth and reproduction and was calculated by the following equation ${ }^{5}$ :

$$
\begin{aligned}
\mathrm{A} & =\mathrm{C} \times \mathrm{AE} \\
\mathrm{SFG} & =\mathrm{A}-\mathrm{R}-\mathrm{U}
\end{aligned}
$$

Where A is energy absorbed from the food, C is the consumed energy, $\mathrm{AE}$ is absorption efficiency, $\mathrm{R}$ is respired energy, and $\mathrm{U}$ is excreted energy.

\section{EXTENDED LONG-TERM GRAZING EXPERIMENT ON HIGHLY CONCENTRATED TOXIC MICROCYSTIS}

Long-term comparative grazing experiment was carried out to evaluate the effects of toxic cyanobacteria on $S$. woodiana feeding and survival. The culturing part of this experiment was conducted in two tanks $(40 \mathrm{~cm} \times 25.2 \mathrm{~cm} \times 26.2 \mathrm{~cm})$ both containing $10 \mathrm{~L}$ of filtered Oita lake water, food suspension, and 10 mussels (shell length of $7.32 \pm$ $0.31 \mathrm{~cm}$ and fresh-weight of $38.34 \pm 4.37 \mathrm{~g}$ ) at controlled conditions $\left(25 \pm 1{ }^{\circ} \mathrm{C}, 12 \mathrm{~h}\right.$ light:dark cycle, 3400 lux) with continuous aeration.

Two types of food were supplied: highly concentrated naturally blooming Oita pond water dominated by Microcystis spp. Containing the high concentration $(25.50 \mu \mathrm{g} / \mathrm{L})$ of toxin; non-toxin green algae Chlorella at the same Chl.a concentration of $424.5 \mathrm{mg} / \mathrm{m}^{3}$ (Table 2). OD (Optical Density) value was measured and food was added every two days to keep the food suspension at the constant concentration.

On 0-day, 3-day, 6-day, and 12-day, the grazing rates and metabolic rates were measured. The filtration rate measurements were performed in $2 \mathrm{~L}$ beakers containing $1 \mathrm{~L}$ corresponding food suspension with three replicates. Six bivalves in each tank were collected on random for each food suspension. And then the selected six bivalves were transferred to 3 replicated $2 \mathrm{~L}$ beakers ( 2 bivalves per beaker) for the filtration rate measurement. After that, respiration rate, absorption efficiency and excretion rate measurements were carried out as described in the previous method part. Finally the SFG values were calculated.

\section{STATISTICAL ANALYSIS}

A paired $t$-test was used to determine the differences in all the bivalve physiological parameters between 0-day and 6-day, respectively. In addition, for all the energy values, the differences between 0-day and 6-day were also tested with the paired $t$-test. The repeated measures ANOVA was used to decide the differences in SFG values between the blooming water group and Chlorella group during 12 days; Multivariate analysis was used to determine the differences between two groups on 
0-day, 3-day, 6-day and 12-day, respectively.

All statistical analyses were carried out with SPSS 16.0 for Windows.

\section{RESULTS}

\section{(1) Phytoplankton abundances and community structure}

The initial phytoplankton was mainly dominated by Microcystis spp., including high densities of unicellular and colonial types.

After 6 days, the total phytoplankton biomass in the control tank decreased slightly compared with that on 0-day. Correspondingly, there was a much more obvious decrease of total phytoplankton biomass, reduced to less than one third of the initial concentration on 6-day in treatment tanks with bivalves, which indicated that the bivalves have significant grazing ability on the eutrophicated pond water.

Through 6 days, Cyanophyceae, Chlorophyceae and Bacillariophyceae showed different variation trends in the control tank and treatment tanks.

Colonial Microcystis spp. has grown to about five times of that on 0-day in the control tank without bivalves; however, in the treatment tanks with bivalves's grazing, there was a slight decrease of colonial Microcystis spp., which indicated the colonial Microcystis spp. can be effectively filtered by $S$. woodiana.

Meanwhile, unicell Microcystis spp. Decreased in the control tank and treatment tanks. It dropped slightly in the control tank, while it decreased more significantly to less than one third of the initial concentration in the treatment tanks, revealing the strong grazing effect of $S$. woodiana on unicell Microcystis spp.

Similarly, Phormidium sp. dropped remarkably in each tank. Whereas, absolute concentrations of Phormidium sp. in the treatment tanks were higher than in the control tank, which indicated that the feeding effect of $S$. woodiana can stimulate the growth of Phormidium sp. in some degree.

For Chlorophyceae, the total biomass in the control tank kept stable, while both the species and total biomass of Chlorophyceae in the treatment tanks went up markedly, revealing that the feeding behavior of bivalves in the favor of the Chlorophyceae growth.

Furthermore, the total biomass of Baclillariophyceae in each tank climbed. The appearance of Cyclotella sp., although of small quantities, indicated the bivalves' feeding behavior benefited the growth of Baclillariophyceae; the biomass of Nitzschia spp. grew up in both cases, while the quantities in the treatment tanks was less than the control tank, reflecting the bivalves' feeding ability on Nitzschia spp..

\section{(2) Scope for growth (SFG) of bivalves}

The weight-specific filtration rate and absorption efficiency of $S$. woodiana on 0-day and 6-day are shown in Fig.1. After 6 days' exposure to Microcystis-blooming water, weight-specific filtration rate increased obviously $(t$-test, $\mathrm{P}<0.05)$, while absorption efficiency was reduced significantly $(t$-test, $\mathrm{P}<0.05)$.

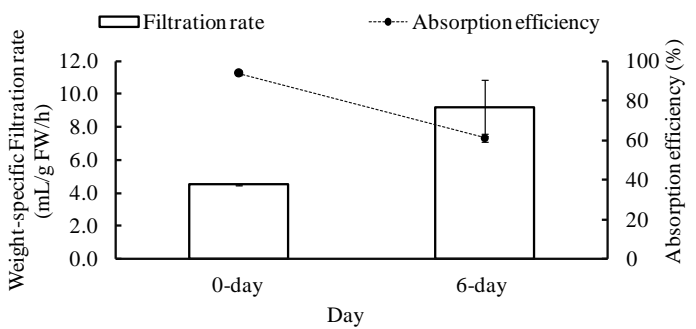

Fig.1 Weight-specific filtration rate $(\mathrm{mL} / \mathrm{g} \mathrm{FW} / \mathrm{h})$ and Absorption efficiency (\%) of S. woodiana on 0-day and 6-day. Error bars are S.D. $(\mathrm{N}=9)$.

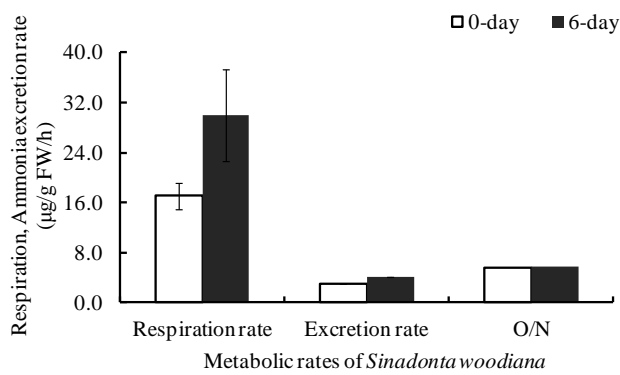

Fig.2 The metabolic rates of S. woodiana on 0-day and 6-day exposed to Microcystis-blooming pond water. Error bars are S.D. $(\mathrm{N}=9)$.

As shown in Fig.2, respiration rate of 6-day was almost twice of that on 0-day. There was a slight but not obvious increase ( $t$-test, $\mathrm{P}>0.05$ ) for ammonia excretion rate and $\mathrm{O} / \mathrm{N}$ ratio through 6 days' exposure. Both $\mathrm{O} / \mathrm{N}$ ratios on 0-day and 6-day fell in the range of 3-16. 


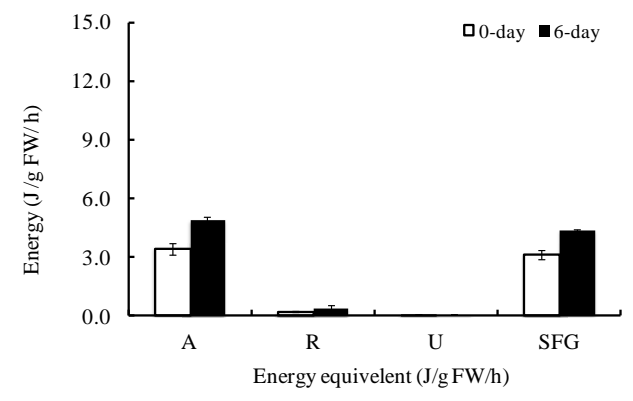

Fig.3 Energy equivalent (J/g FW/h) of the physiological responses of $S$. woodiana on 0-day and 6-day. A: energy absorbed from the food; R: energy consumed by respiration; U: energy consumed by ammonia excretion; SFG: energy available for growth.

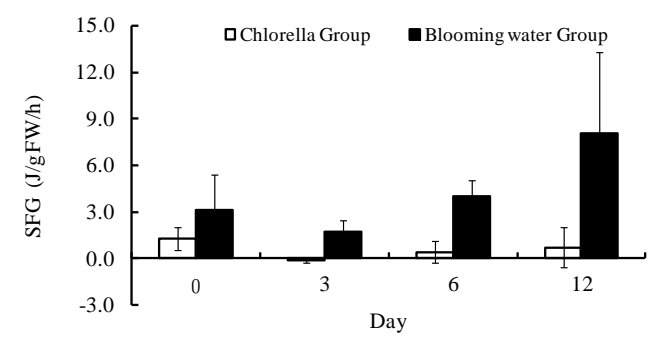

Fig.4 SFG (J/g FW/h) of $S$. woodiana on different days when they were fed with Chlorella and blooming water at the same constant concentration of Chlorophyll a, SFG: energy available for growth.

The energy equivalents of mussels are presented in Fig.3. SFG in mussels was significantly increased ( $t$-test, $\mathrm{P}<0.05$ ), mainly contributed by the increasing filtration rate, whereas the energy respired and excreted was not greatly affected after 6 days' exposure.

\section{(3) Extended long-term grazing responses of $S$. woodiana}

S. woodiana SFG on toxic Microcystis ranged from 1.7 to $8.0 \mathrm{~J} / \mathrm{g} / \mathrm{h}$ and on non-toxic Chlorella ranged from -0.1 to $1.3 \mathrm{~J} / \mathrm{g} / \mathrm{h}$, (Fig.4), with mean values of 4.2 and $0.6 \mathrm{~J} / \mathrm{g} / \mathrm{h}$, respectively. No bivalve mortality was registered on both Clorella group and blooming water group.

A slightly decrease of SFGs was observed on 3-day for both food groups. However, S. woodiana SFGs throughout the 12-day exposure to toxic Microcystis did not decrease significantly ( $>0.05$, ANOVA), indicating there is no negative effects of cyanobacteria toxicity on $S$. woodiana growth.

SFGs of $S$. woodiana throughout 12 days' exposure to two food suspension vary significantly (repeated measures ANOVA, $\mathrm{P}<0.05)$ and meanwhile the variation trends over time were similar for two food groups.

In addition, on 0-day, the SFGs were not statistically different between two groups (multivariate analysis, $\mathrm{P}>0.05$ ), nevertheless, on 3-day, 6-day and 12-day, the SFGs of blooming water group were significantly (multivariate analysis, $\mathrm{P}<0.05$ ) higher than them of Chlorella group, indicating that $S$. woodiana grew better feeding on toxic cyanobacteria than Chlorella.

\section{DISCUSSION}

\section{(1) Phytoplankton abundances and community structure}

This experiment is performed to illustrate the feeding activity effect on phytoplankton community in microcosm experiments. Obviously, $S$. woodiana can effectively control the total biomass of phytoplankton through feeding activity, especially colonial and unicellular Microcystis spp..

The interaction between bivalves and phytoplankton communities is complex, particularly because bivalves can affect algal community composition both directly and indirectly ${ }^{15}$. The direct effects of mussel activities on the phytoplankton community include: (1) selective removal (preferential clearance); (ii) selective ingestion (pre-ingestive selection in the mantle cavity); or (iii) differential digestion (post-ingestive selection) of phytoplankton. Indirectly the mussels could alter phytoplankton communities by (1) altering nutrient or light regimes in a way that may favor certain phytoplankton groups; (2) by removing phytoplankton from the water column at such a high rate that faster growing species will become relatively more abundant ${ }^{15}$.

Direct and indirect mechanisms may act simultaneously and a resultant change in phytoplankton species composition at the whole-system level could be caused by a combination of all of these effects ${ }^{15)}$.

Thus, the different responses of different species of algae to bivalves' grazing behavior might be caused by the bivalves' feeding selectivity. As for many freshwater and marine suspension feeders, feeding-process of mussels is influenced by food quality and food quantity ${ }^{16)}$.

In the case of algal suspensions, food quantity can be expressed as Chl.a concentration and particulate organic matter (POM). Food quality can be expressed in different ways: organic: inorganic ratio of seston ${ }^{17)}$, toxin content ${ }^{18)}$ and also polyunsaturated 
fatty acids (PUFAs) content ${ }^{19)}$. The shape and size of algal cells are also parameters that potentially affect the feeding behavior of mussels.

In the control tank, although cultured in the same conditions, different species of algae demonstrated different variation trends, probably due to the different competitive abilities and growth speeds. The colonial Microcystis has higher photosynthesis capability, due to its more visible vacuoles and less lipid droplets, which make colonial M. aeruginosa has better buoyancy ability for migration than single cell $M$. aeruginos $a^{20)}$. Furthermore, vertical migration provides competitive advantages for colonial $M$. aeruginosa. Therefore, during only 6 days, the colonial Microcystis spp. can grew rapidly. For Phormidium sp. and unicellular Microcystis spp., the obvious decrease can be caused by the weak adaptation and competitive abilities in the laboratory microcosm. The similar phenomenon was reported by Yang et $\mathrm{al}^{3)}$. In their study, it was also found that in the control buckets without bivalves, Microcystis spp. (not mention unicellular type or colonial type) declined obviously during one week.

Nevertheless, the laboratory microcosm method is still popularly used on the study of bivalves feeding selectivity and SFG measurement. It enables us to use naturally blooming water in the lab microcosm, isolated from other environmental variables, and evaluate the bivalve feeding effect on phytoplankton community. Thus, it can cover the shortage of aggregating ability deficiency for pure cultured $M$. aeruginosa under laboratory conditions.

\section{(2) Impacts of Microcystis-blooming water on bivalves}

The weight-specific filtration rates of $S$. woodiana values obtained in this study were similar to the values obtained by $\mathrm{Wu}$ et al. ${ }^{21)}$ who showed that the filtration rates of different bivalves (with individual weight ranging from $50 \mathrm{~g}$ to $100 \mathrm{~g}$ ) ranged from 2.5 $\mathrm{mL} / \mathrm{g} \mathrm{FW} / \mathrm{h}$ to $9.0 \mathrm{~mL} / \mathrm{g} \mathrm{FW} / \mathrm{h}$.

Larger filtration rate on Microcystis-blooming pond water was accompanied by larger oxygen consumption rate which supplied energy for active feeding behavior.

Of the $\mathrm{N}$ absorbed by bivalves from the ingested food, the majority is used for tissue growth and some is excreted as urine (70\% of which is $\mathrm{NH}_{4}{ }^{+}, 0 \%$ to $13 \%$ urea, and $5 \%$ to $21 \%$ amino-N) ${ }^{14)}$. Feeding and metabolic behavior are effected each other.

$\mathrm{O} / \mathrm{N}$ represents the degree to which protein is utilized in energy metabolism by invertebrates. They were all in the range of 3-16, which indicated protein was the main metabolic substrate ${ }^{22)}$ from 0-day to 6-day. As mentioned before, large quantities of Microcystis spp. were removed by the bivalves as the main food.

Table 2 Characteristics of the experimental cyanobacteria diet fed to Sinanodonta (Anodonta) woodiana.

\begin{tabular}{|c|c|c|c|c|c|c|}
\hline Cyanobacteria & Shape & Origion & $\begin{array}{c}\text { Intracellunar } \\
\text { Microcystin } \\
(\mu \mathrm{g} / \mathrm{L})\end{array}$ & $\begin{array}{c}\text { Extracellunar } \\
\text { Microcystin } \\
(\mu \mathrm{g} / \mathrm{L})\end{array}$ & $\begin{array}{c}\text { Total } \\
\text { Microcystin } \\
(\mu \mathrm{g} / \mathrm{L})\end{array}$ & $\begin{array}{r}\text { Chl.a } \\
\left(\mathrm{mg} / \mathrm{m}^{3}\right)\end{array}$ \\
\hline Microcystis aeruginosa NIES-90 (cultured) & Unicell & Reference 4) & - & - & 1.55 & 38.7 \\
\hline Microcystis spp. (naturally blooming) & Colony and Unicell & This study & - & 0.36 & - & 120.0 \\
\hline Microcystis spp. (naturally blooming) & Colony and Unicell & A pond, Oita, Japan & 25.14 & 0.36 & 25.50 & 424.5 \\
\hline
\end{tabular}

: means not measured. Analyses of microcystins (MC-LR) were performed using an ELISA assay test kit (Tokiwa Chemical Industries Co., LTD.).

Furthermore, in the study of de la Fuente G. et al., t the nutritional characteristics of Microcystis spp. that occurs naturally in a Guatemalan lake were determined and the sun-dried material proved to have a high protein content $55.6 \%^{23)}$. Thus, from 0-day to 6-day, the algae filtered by the bivalves as main food had high proteins content, which probably induced the $\mathrm{O} / \mathrm{N}$ ratios both on 0-day and 6-day to fall in the range of 3-16.

After 6 days' filtration, Microcystis spp. in the treatment tanks were decreased obviously, which means the high nutrimental food with $55.6 \%$ protein content for $S$. woodiana was less than one third of that on the 0-day. Thus, absorption rate for $S$. woodiana was decreased due to the low nutrimental content of food in pond water. Meanwhile, in order to acquire enough energy to maintain metabolic activity, filtration rates were increased through the increased volume of filtered water that passed the gill of $S$. woodiana.

With regard to the microcystins (MCs) effect on $S$. woodiana's physiological behavior, the characteristics of the experimental cyanobacteria diet used in our three different experiments were shown in Table 2. All the toxin measurement in the enzyme-linked immunosorbent assay (ELISA) method did not allow separate quantification of MC-LR or MC-LF but gave a total estimation of MCs presented in cyanobacterial suspensions.

In the previous study with cultured Microcystis aeruginosa NIES-90, which contained the total MCs in a small quantity $(1.55 \mu \mathrm{g} / \mathrm{L})$ in the short-term grazing effect experiment, it was found that the toxic $M$. aeruginosa did not restrain the grazing behavior of $A(S)$. woodiana, instead supplied the highest SFG value for the mussel's growth. Furthermore, we 
supplied the possible reason that in some degree, the mussel $A(S)$. woodiana could accumulate and depurate MCs, although, we could not distinguish whether it was MC-LR or the MC-LF variant ${ }^{4)}$.

In the 6-day feeding experiment on naturally blooming water in this study, $20 \mathrm{~mL}$ Microcystis-blooming water was collected for MCs analysis. After filtered with GFC filter paper (Whatman), the filtered water sample was measured for the extracellular MCs concentration with ELISA assay test kit. (Tokiwa Chemical Industries Co. LTD.) and the value was $0.36 \mu \mathrm{g} / \mathrm{L}$ in this study. As reported by Dittmann and Borner that the extracellular MCs are usually $<10 \%$ of total $\mathrm{MCs}^{24)}$, thus the total MCs of the diet suspension used in this study may be estimated higher than $3.6 \mu \mathrm{g} / \mathrm{L}$.

After 6-day exposure to the toxic Microcystis blooming water $(\mathrm{MCs}>3.6 \mu \mathrm{g} / \mathrm{L})$, significantly increased SFG for $S$. woodiana was observed, mainly due to the increasing filtration rate as shown in Fig.3. It can be inferred that MCs in this study did not restrain the filtration rate and the potential growth of S. woodiana.

\section{(3) Extended long-term grazing responses of $S$. woodiana}

Extended long-term comparative grazing experiment showed that there was not a decrease in $S$. woodiana SFG under exposure to toxic Microcystis. It indicated that $S$. woodiana assimilated cyanobacteria cells during the 12-day experiment and no toxic effect could be observed.

It was also noticed that compared with the non-toxin green algae Chlorella, the toxic naturally blooming water supplied much higher potential growth energy for the bivalves.

In addition, no mussel mortality was registered. The assimilation of highly concentrated toxic Microcystis by $S$. woodiana suggested that this bivalve presents survival mechanisms in face of toxins. Therefore, cyanobacteria toxicity has no negative effect on $S$. woodiana survival and growth.

A similar experiment with zebra mussel indicated higher filtration rates on toxic Microcystis than on non-toxic food (Nannochlopsis) with no mussels mortality in a 3-week assimilation period (MC-LR concentration $=11.7 \mu \mathrm{g} / \mathrm{L}^{25}$, which endorse our results.

In previous studies, the ability of bivalves to accumulate and store toxins has been demonstrated in some studies ${ }^{26)}$. One possible explanation is that microcystins can be detoxified through the conjugation of the toxin with the enzyme glutathione via soluble GST (glutathione-S-transferases), which was shown in several aquatic organisms, including zebra mussel ${ }^{27)}$.
Another possibility is that the ingestion of intact cells could be less toxic to mussels. Vasconcelos et al. found that intact Microcystis cells did not induce any major response (GST activity) from mussel Mytilus, indicating mussels are quite resistant to cyanobacteria when those cells are intact ${ }^{28)}$.

\section{CONCLUSIONS}

It can be inferred that during the 6-day exposure to naturally Microcystis-blooming pond water, both unicellular and colonial Microcystis spp. can be effectively removed by $S$. woodiana. It also indicated that $S$. woodiana can grow well after their feeding, demonstrated by the increased SFG value.

Combined with the extended long-term grazing experiment results, that the toxic Microcystis supplied much more energy for $S$. woodiana's potential growth; on the other hand, $S$. woodiana can survive and showed strong adaptation ability when it was exposed to toxic Microcystis solution

Therefore, the bivalve $S$. woodiana, which is widely distributed throughout Chinese and Japanese freshwaters, can be promoted as a tool in biomanipulation of eutrophic lakes in China and Japan associated to its powerful filtering capacity on suppression of Microcystis spp. and adaptation ability when exposed to toxic Microcystis-blooming water.

ACKNOWLEDGEMENT: This research was financially supported in part by "the Kyushu University's commemoration project for the 2012 Centenary" and by a grant from Mitsubishi Corporation.

\section{REFERENCES}

1) Zhao, Y., Chen, X. B., Yang, J. and Liu, H. B. : The species identification of three Anodonta woodiana species based on sequence differences of ND1 and ITS1 genes, Oceanologia et Limnologia Sinica, Vol. 42, No. 4, pp. 619-624, 2011 (in Chinese).

2) Liu, Y. Y., Zhang, W. Z. and Wang, Y. X. : Economic fauna of China, Freshwater mollusk, pp. 107-108, Beijing: Science Press, 1979 (in Chinese).

3) Yang, D. M., Chen, Y. W., Liu, Z. W, et al. : Top-down effects of Anodonta woodiana on the nutrient concentration and phytoplankton community composition in a microcosm ecosystem, Lake Sciences, Vol. 20, No. 2, pp. 228-234, 2008 (in Chinese).

4) Liu, Y. X., Hao, A. M., Iseri, Y., Kuba, T. and Zhang, Z. J. : A comparison of the Mussel Anodonta woodiana's acute physiological responses to different algae diets, $20134^{\text {th }}$ International Conference on Environmental Engineering 
and Applications-ICEEA 2013, Singapore, 24-25 August, 2013. (Accepted and to be published).

5) Widdows, J., Donkin, P., Brinsley, M. D., et al. : Scope for growth and contaminant levels in North Sea Mussels Mytilus edulis, Marine Ecology Progress Series, Vol. 127, pp. 131-148, 1995.

6) Bayne, B. L. and Newell, R. C. : Physiological energetics of marine molluscs, In Wilbur, K. M. and Salenddin, A. S. M. (Ed.), The mollusca, Vol. 4. Physiology (1): pp. 406-515, London: Academic Press, 1983.

7) Smaal, A. C. and Widdows, J. : The scope for growth of bivalves as an integrated response parameter in biological monitoring, In Kramer, J. M. (Ed.), Biomonitoring of coastal waters and estuaries, pp. 247-267, Boca Raton: CRC Press, 1994.

8) Hirose, H. and Yamagishi, T. (Ed.), Illustration of the Japanese freshwater algae, Tokyo: Uchida Rokakuho Press, 1977 (in Japanese).

9) Coughlan, J. : The estimation of filtering rate from the clearance of suspension, Marine Biology, Vol. 2, pp. 356-358, 1969.

10) Widdows, J. and Johnson, D. : Physiological energetics of Mytilus edulis: scope for growth, Marine Ecology Progress Series, Vol. 46, pp. 113-121, 1988.

11) Gnaiger, E. : Heat dissipation and energetic efficiency in animal anoxibiosis: economy contra power, Journal of Experiment and Zoology, Vol. 228, pp. 471-490, 1983.

12) Conover, R. J. : Assimilation of organic matter by zooplankton, Limnology and Oceanography, Vol. 11, pp. 338-345, 1966.

13) Widdows, J. : The effects of stress and pollution on marine animals, In Bayne B. L. et al. (Ed.), Physiological measurements and Physiological procedures, pp. 3-45 and 161-178, New York: Praeger Press, 1985.

14) Bayne, B. L., Thompson, R. J. and Widdows, J. : Physiology II . In Bayne, B. L. (Ed.), Marine mussels, their ecology and physiology, pp. 207-260, New York: Cambridge University Press, 1976.

15) Bastviken, D. T. E., Caraco, N. F., and Cole, J. J. : Experimental measurements of zebra mussel (Dreissena polymorpha) impacts on phytoplankton community composition, Freshwater Biology, Vol. 39, No. 2, pp. 375-386, 1998.

16) Hawkins, A. J. S., Fang, J. G., Pascoe, P. L., Zhang, J. H., Zhang, X. L., et al. : Modeling short-term responsive adjustments in particle clearance rate among bivalve suspension-feeders: separate unimodal effects of seston volume and composition in the scallop Chlamys farreri, Journal of Experimental Marine Biology and Ecology, Vol. 262, No. 1, pp. 61-73, 2001.

17) Schneider, D. W., Madon, S. P., Stoeckel, J. A., and Sparks, R. E. : Seston quality controls zebra mussel (Dreissena polymorpha) energetics in turbid rivers, Oecologia, Vol. 117, No. 3, pp. 331-341, 1998.
18) Engstrom, J., Viherluoto, M., and Viitasalo, M., : Effects of toxic and non-toxic cyanobacteria on grazing, zooplanktivory and survival of the mysid shrimp Mysis mixta, Journal of Experimental Marine Biology and Ecology, Vol. 257, No. 2, pp. 269-280, 2001.

19) Demott, W. R., and Muller-Navarra, D. C. : The importance of highly unsaturated fatty acids in zooplankton nutrition: evidence from experiments with Daphnia, a cyanobacterium and lipid emulsions, Freshwater Biology, Vol. 38, No. 3, pp. 649-664, 1997.

20) Sherman B. S. and Webster I. T. : A model for the light-limited growth of buoyant phytoplankton in a shallow, turbid waterbody, Australian Journal of Marine and Freshwater Research, Vol. 45, No. 5, pp. 847-862, 1994.

21) Wu, Q. L., Chen, Y. W and Liu, Z. W. : Filtering capacity of Anodonta woodiana and its feeding selectivity on phytoplankton, Chinese Journal of Applied Ecology, Vol. 16, No. 12, pp. 2423-2427, 2005 (in Chinese).

22) Mayzaud, P. and Conover, R. J. : O:N atomic ratio as a tool to describe zooplankton metabolism, Marine Ecology Progress Series, Vol. 45, pp. 289-302, 1988.

23) De la Fuente, G., Flores, A., Molina, M. R., Almengor, L., and Bressani, R. : Some nutritional characteristics of a naturally occurring alga (Microcystis sp.) in a Guatemalan lake, Applied and Environmental Microbiology, Vol. 33, No. 1, pp. 6-9, 1977.

24) Dittmann, E. and Borner T. : Genetic contributions to the risk assessment of microcystin in the environment, Toxicology and Applied Pharmacology, Vol. 203, No. 3, pp. 192-200, 2005.

25) Dionisio Pires, L. M., Karlsson, K. M., Meriluoto, J. A. O., Kardinaal, E., Visser, P. M., Siewertsen, K., Van Donk, E. and Ibelings, B. W. : Assimilation and depuration of microcystin-LR by the zebra mussel, Dreissena polymorpha, Aquatic Toxicology, Vol. 69, No. 4, pp. 385-396, 2004.

26) Yokoyama, A. and Park, H. : Depuration kinetics and persistence of the cyanobacterial toxin microcystin-LR in the freshwater bivalve Unio douglasiae, Environmental Toxicology, Vol. 18, No. 1, pp. 61-67, 2003.

27) Pflugmacher, S., Wiegand, C., Oberemm, A., Beattie, KA., Krause, E., Codd, GA. and Steinberg, CE., : Identification of an enzymatically formed glutathione conjugate of the cyanobacterial hepatotoxin microcystin-LR: the first step of detoxication, Biochimica et Biophysica Acta, Vol. 425, No. 3, pp. 527-533, 1998.

28) Vasconcelos, V. M., Wiegand, C. and Pflugmacher, S. : Dynamics of glutathione-S-transferases in Mytilus galloprovincialis exposed to toxic Microcystis aeruginosa cells, extracts and pure toxins, Toxicon, Vol. 50, No. 6, pp. 740-745, 2007.

(Received May 24, 2013) 